\title{
Review of Scientific Self-Experimentation: Ethics History, Regulation, Scenarios, and Views Among Ethics Committees and Prominent Scientists
}

\author{
Brian P. Hanley,' William Bains, and George Church ${ }^{3}$
}

\begin{abstract}
We examine self-experimentation ethics history and practice, related law, use scenarios in universities and industry, and attitudes. We show through analysis of the historical development of medical ethics and regulation, from Hippocrates through Good Clinical Practice that there are no ethical barriers to self-experimentation. When the self-experimenter is a true investigator, there is no other party to be protected from unethical behavior. We discuss the $n$-of- 1 issue in self-experiments, and make suggestions for improving experiment design. We discuss real-world scenarios of self-experimentation: at universities, for independent single-subject investigators, investigator/employees at pharmaceutical firms, and nonscientist self-experimenters. Our survey of ethics committees regarding policy and review for self-experimenting investigators show that approximately one-third of ethics committee respondents had a policy regarding self-experimentation, and one-third did not require ethical committee review of proposed experiments. There was no relationship between having a policy and asking for review. We also surveyed member attitudes to, and experiences of, self-experimentation among members of the National Academy of Sciences, Royal Society, and European Academy of Sciences. To our knowledge, this survey is the first breakdown of self-experiments into impact-relevant type classifications, and represents an advance in the field. Half of our scientist respondents performed self-experiments, and roughly one-fifth had conducted serious self-experiments. Most responders thought self-experiments were valuable, however, biologics injections, radiation exposure, and surgical implants had negative ratings greater than positive. We conclude that selfexperimenters should not have attempts made to terminate them, bar them from use of facilities, nor be barred from using themselves or their tissues except in exceptional circumstances. Organizational uncertainty over the ethical and regulatory status of self-experimentation, and resulting fear of consequences is unjustified and may be blocking a route to human experiments that practicing scientists widely consider appropriate, and which historical precedent has shown is valuable.
\end{abstract}

Keywords: ethics, research history, human research, medical ethics; self-experimentation, n-of-1

\section{Introduction}

“...I didn't really discuss it with my bosses in case they forbade me to do it."-Barry Marshall

\section{Why this article?}

Many informal discussions have led us to see that selfexperimentation is widely considered ethically questionable and unscientific. Self-experimenters have had difficulty with publication, attacks by members of the press, and serious problems with their institution. Even Barry Marshall, who won a Nobel afterward for the relationship of Helicobacter pylori to ulcers, did not tell his institution what he was doing. ${ }^{1}$ Werner Forßmann was terminated after showing cardiac catheterization could be done safely by testing it on himself. His superior hoped to prevent him ever practicing medicine again. Forßmann suffered attacks for much of his life afterward, his Nobel Prize notwithstanding. ${ }^{2}$

In private discussions, many highly regarded scientists admitted they had done self-experiments. Virtually all that we spoke to were unwilling to be identified. Some strenuously warned us against it, telling horror stories of institutional

\footnotetext{
${ }^{1}$ Butterfly Sciences, Davis, California.

${ }^{2}$ Rufus Scientific Ltd., Hertsfordshire, United Kingdom.

${ }^{3}$ Department of Genetics, Harvard Medical School, Boston, Massachusetts.
} 
Table 1. Nobel Prizes of Self-Experimenters

\begin{tabular}{|c|c|c|c|}
\hline Recipient & Year & Prize & Self-experiment \\
\hline Neils Finsen & 1903 & Phototherapy & Tested effects of sunlight and fractions of sunlight. \\
\hline William Ramsay & 1904 & Discovery of inert elements & Tested anesthetic effect of gases to find new ones. \\
\hline Elie Mechnikoff & 1908 & Phagocytes & $\begin{array}{l}\text { Injected himself with Borellia to help find cause of } \\
\text { relapsing fever. }\end{array}$ \\
\hline Frederick Banting & 1923 & $\mathrm{I}$ & Gave himself mustard gas burns to test treatment. \\
\hline Charles Nicolle & 1928 & Cause of Typhus & Exposed himself to typhus to prove Koch's postulates. \\
\hline Karl Landsteiner & 1930 & Blood types & Tested his own blood for blood type research. \\
\hline Gerhard Domagk & 1939 & Sulfa drugs & Injected himself with sterilized human $\mathrm{c}$ \\
\hline Ernest Lawrence & 1939 & Cyclotron & $\begin{array}{l}\text { Drank water with radioactive sodium to examine sodium } \\
\text { circulation. }\end{array}$ \\
\hline George de Hevesy & 1943 & Polar & Drank heavy water to determine half-life of $\mathrm{H}_{2} \mathrm{O}$ in the body. \\
\hline Max Theiler & 1951 & Yellow Fever & Tested yellow fever vaccine \\
\hline Albert Schweitzer & 1952 & Humanitarianism & Tested yellow fever vaccine \\
\hline Werner Forßmann & 1956 & Cardiac catheterization & Cardiac catheterized himself to show it could $b$ \\
\hline Rosalyn Yalow & 1977 & $A C T H$ & Tested her own blood in her ACTH research \\
\hline Barry Marshall & 2005 & Helicobacter pylori and ulcers & Drank a culture of $H$. pylori \\
\hline
\end{tabular}

Lines in italics experimented in the area for which they won a Nobel Prize.

attempts to fire them. Others verbally "tap-danced," not even trusting friendly colleagues with details for fear of blowback.

Why this hostility? There are two broad classes of reasons suggested by our discussions: the belief that selfexperimentation is unethical and the belief that it is ineffective. In this article we discuss ethics and effectiveness. Our conclusion is that self-experimentation is scientifically legitimate and ethically sound. We will begin with an overview of self-experiment ethics history to the present.

\section{Self-experimentation-historical perspective through the twentieth century}

Self-experimentation has a long and noble history that has led to many discoveries, seven of which have been worthy of a Nobel Prize, as shown in Table $1 .^{2-6}$

The history of scientific testing, where the primary or lead investigator used themselves as a research subject, goes back centuries (Fig. 1). Allen Weisse documented 465 cases of scientific self-experimentation up to 2003, and 8 deaths from self-experiments, though none after 1928. ${ }^{4}$ Weisse used two books as his data source, the second published in 2003. ${ }^{3,7}$ He missed Max Theiler's 1951 Nobel Prize, Barry
Marshall's 2005 Nobel came after, and we removed Victor Hess, which gives us 14 Nobel prizes for self-experimenters, 7 of them in the area of their Nobel Prize.

Per Weisse' sources, since 1975 there have been at least 40 self-experiments by scientists. We believe that there are certainly many times that number. ${ }^{8}$

\section{Self-experimentation in the twenty-first century}

Self-experimentation continues to be carried out in the $21 \mathrm{st}$ century. Publication is rare, but of the published work, in addition to Barry Marshall's, ${ }^{5}$ in 2010 we know of Michael Snyder's "Snyderome" project, ${ }^{9}$ and Huber et al. testing of a burn ointment. ${ }^{10}$ In 2011-2012, Gwern tested micro doses of lysergic acid diethylamide (LSD) on himself. ${ }^{11}$ In 2014, Philip Kennedy had electrodes implanted into his speech center. ${ }^{12}$ From 2012 to 2014, Russell Poldrack performed magnetic resonance imaging scans of himself. ${ }^{13}$ In 2015 and 2016, Brian Hanley, the lead author, tested a gene therapy on himself. In 2016, Alex Zhavoronkov discussed self testing of drugs that his software algorithms identified as likely candidates. ${ }^{14}$ These examples are, again, a small sampling based on what is documented: our discussions with practitioners (discussed below)

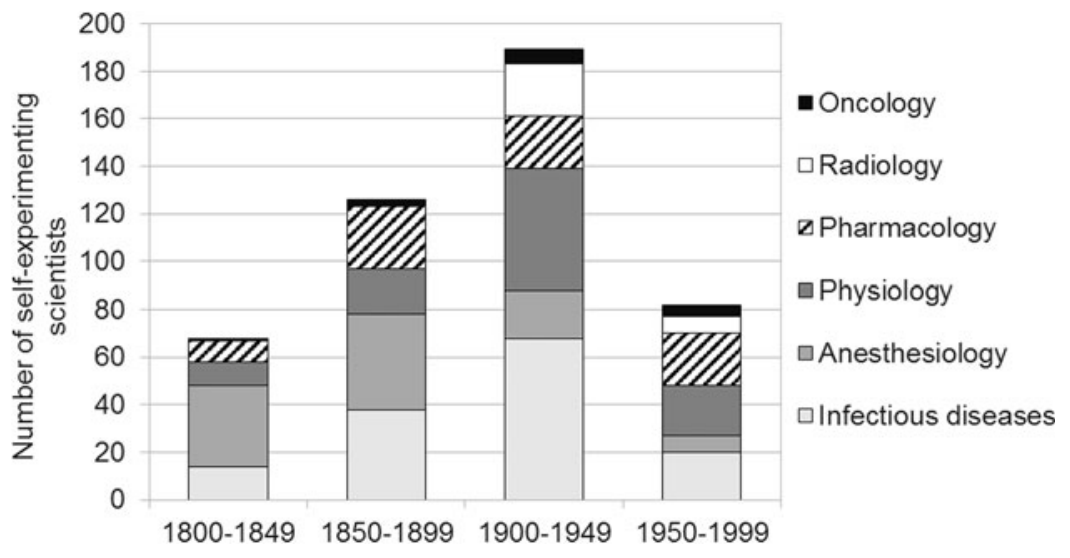

FIG. 1. Documented self-experiments 1800-1999. 
suggest that the large majority of self-experimentation is undocumented, at least in the formal scientific literature.

Let us start our examination by following the development of modern medical ethics and thereby lay the groundwork for understanding the place of self-experimentation within modern ethical thought.

\section{Ethics Development in Medicine-Hippocrates to the Twenty-First Century}

The overall ethics precedence tree is shown in Figure 2. Although there are Egyptian writings that predate it, ${ }^{15}$ Hippocrates is generally accepted as the foundation of modern biomedical ethics.

\section{Hippocratic oath-the historical root}

Few physicians today swear an oath to, "Apollo, Physician, Asclepius, Hygieia, Panaceia and all the gods and goddesses," which is the oldest currently recognized ethical code in medicine (See Appendix). ${ }^{16}$ Some of the oath is considered archaic, however, core Hippocratic principles are retained: to do no harm; to put the interests of the patient first; to not commit injustice toward patients; to not engage in sex with patients under care; and to keep patient matters strictly confidential.

The Hippocratic oath did not have the force of law, and subsequent medical ethics codes similarly were mostly a matter of culture and practice. Thomas Percival's 246 page book published in 1803 defines conduct with patients, colleagues, and pharmacists in detail. ${ }^{17}$ The Royal College of Physicians adopted his text, republished in 1847. It was adopted by the American Medical Association in $1849^{18}$ as formal regulatory principles. Germany and Russia both had laws regarding medical ethics in experimentation in the first half of the 20th century. ${ }^{19}$

\section{Nuremberg principles-the turning point based on outrages}

The formalization of modern ethical practice in biomedicine is rooted in a series of outrages that occurred in the 20th century wherein people were used as test subjects and suffered terrible consequences, either against their will or unwittingly. In particular, Nazi prisoner experiments led to

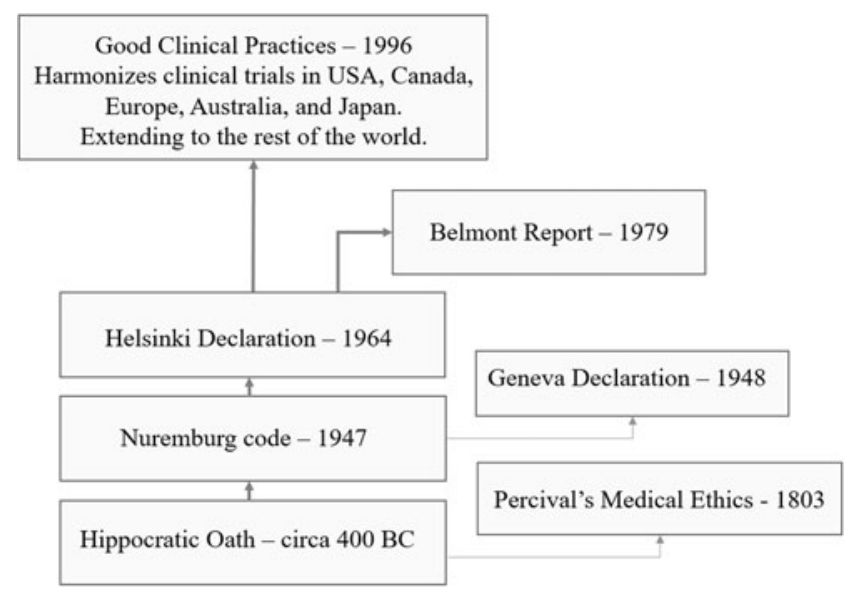

FIG. 2. Clinical ethics documents precedence tree. war crimes trials in 1945-1946 that used the Hippocratic Oath and other precedents as a basis to formulate the Nuremberg principles of 1947 for protection of medical research subjects. ${ }^{20}$ The Nuremberg principles make explicit the Hippocratic dictum that doctors should "do no harm," medical practice should be for the benefit of the patient, and if for research that does not directly benefit the patient, it should not harm the patient. Nuremberg also requires patient consent. The Nuremberg principles are the foundation reference of modern medical ethics. The critical Principle for our purposes is number 5 :

5. No experiment should be conducted where there is an a priori reason to believe that death or disabling injury will occur, except, perhaps, in those experiments where the experimental physicians also serve as subjects.

-Nuremberg court, principles of human experimentation ${ }^{20}$

Article 5 of the Nuremberg principles is the only direct address to self-experimentation in medical ethics regulation. Since article 5 covers the case where disabling injury or death could occur, by extension it also covers lesser risks to self. We should emphasize that the Nazi experiments, while the best known, are not the only ethically indefensible medical research done in the mid-20th century. Imperial Japan conducted such experiments as well. ${ }^{21}$ British, Australian, and American soldiers were deliberately exposed to high levels of radiation during the 1940s and 1950s. ${ }^{22,23}$ And as late as 2010, a study conducted from 1946 to 1948 by the United States Public Health Service (PHS) and the Pan American Health Organization came to light that had deliberately infected Guatemalans with sexually transmitted diseases such as syphilis and gonorrhea from 1946 to $1948 .^{24}$

\section{Declaration of Helsinki-formalization based on Nuremberg}

The 1964 Declaration of Helsinki was the first major public effort by medical scientists to codify the responsibilities of medical experimenters. ${ }^{25}$ Helsinki eased the requirements for consent, modifying Nuremburg's "absolutely essential" to "if at all possible," and allowing proxy consent from a legal guardian. The 2008 version of the Helsinki Declaration includes the word "consent" 20 times and the 2013 version $27{ }^{25,26}$ Article 14 of Helsinki defined that a clinical protocol should be a written document, kept up to date with revisions approved by a review committee, and inform subjects of conflict of interest and risk. Helsinki's guidelines remained voluntary for 10 years in the United States.

The Belmont Report of 1979 on human subjects, based on the Helsinki Declaration, laid out "respect for persons, beneficence, and justice," and informed consent without coercion, as the guiding principles of ethics committees. ${ }^{27}$

\section{Quis custodiet ipsos custodies?}

The formalization of ethical codes called for a process by which adherence to those codes could be monitored, and sanctions applied if codes were broken. In much of Europe, the review function is held by the Institutional Ethics Committee, also known by other names. The Netherlands uses Medical Research Ethics Committee, Sweden the Ethical Vetting Board (Etikprövningsnämnden), France the Comités de Protection des Personnes, Canada the Research Ethics Board, Australia 
the Human Research Ethics Committee, and Research Ethics Committee is the name in Italy, Spain, Portugal, Germany, the United kingdom, and Ireland. In Japan it is 倫理委員会, or, in English, ethics committee. Regions may also have colloquial names. These are equivalent to the Institutional Review Board (IRB) in the United States, constituted to fulfill the purpose laid out in the Helsinki Declaration.

\section{Public law on research ethics committees-prompted by further outrages from within}

The United States system is a response to abuses in the 1960s, revealed in 1972, when Peter Buxtun, a former employee of the United States PHS, publicly revealed that he had complained about unethical treatment of subjects in the Tuskegee study since $1966 .^{28}$ This led to public law 93-348 in the United States in 1974, which created the National Commission for the Protection of Human Subjects of Biomedical and Behavioral Research. ${ }^{29}$ This law required ethics approval before conducting any human experiments with federal money or before conducting any clinical trials, whether public or private. Other countries followed. Germany formalized this requirement in $1994 .^{30}$ Japan's first formal ethics committee was established in 1982, but regulations requiring it for clinical trials waited until 2003 . $^{3}$

\section{Good clinical practices-worldwide harmonization of practices}

In late 2008, the United States of America's Food and Drug Administration (FDA) modified regulations so they no longer refer to the Helsinki documents, and instead refer to good clinical practices (GCP). ${ }^{32}$ GCP is a broader set of requirements that includes regulations on a wide range of aspects of clinical research conduct, including such matters as traceability of methods and materials, data collection and handling, and trial reporting, all aimed at ensuring that clinical experiments generate valid data while minimizing risk to patients. GCP is principally aimed not only at clinical tests of new drugs, devices, or procedures, but also applies to "pure" experimentation. GCP is a product of the International Conference on Harmonization (ICH) of 1996 and 2015 that aligns clinical trials in the United States, Canada, Australia, Europe, and Japan. Other countries working toward inclusion in this harmonization include Russia, Ukraine, Eastern Europe, Central Asia, ${ }^{33}$ China, $^{34}$ and India. ${ }^{35}$ GCP did not jettison Helsinki as some think. "Guidance for Industry E6 Good Clinical Practice: Consolidated Guidance'” of 1996, release 1 (R1), and the 2015 draft release 2 (R2), are built on Helsinki. (See introduction, section 2.1 , and section $4.81 .^{36,37}$ )

Clinical trials should be conducted in accordance with the ethical principles that have their origin in the Declaration of Helsinki, and that are consistent with GCP and the applicable regulatory requirement(s).

- ICH GCP (R1 and R2). ${ }^{36,37}$

Helsinki, in turn, references Nuremberg as its foundation. However, not all jurisdictions accept later versions of the Helsinki document, which is why we cite both the 2008 and 2013 versions.

GCP requires external review of protocols to ensure the interests of patients/subjects are protected. This review is the ethics committee's role.
In January of 2017, the United States of America's FDA published modifications taking effect in 2018 to exempt certain low-risk studies from IRB review, and make other low-risk study IRB reviews limited to privacy. ${ }^{38}$

\section{Summary of ethics committee's role}

In summary, the primary purpose of an ethics committee review is to protect potential research subjects from investigators and bureaucracy acting without conscience, or implementing dangerous protocols without proper consideration. Secondarily, ethics committee review should ensure subjects obtain benefit and are protected from undue pressure. In addition, ethics committee proceedings are records of experimental protocols that may have historical value.

However, the history and logic of the modern system is often forgotten when discussing medical ethics, with discussions becoming focused on what committees will do rather than on why they might do it. Putting their constitution into historical context is therefore essential.

\section{Other forms of legal responsibility-independent laws that may impact institutions}

The United Kingdom's “Corporate Manslaughter and Corporate Homicide Act of 2007," holds corporations responsible for death of those for whom they have a "Duty of Care." Universities and the National Health Service are "Crown bodies," and hence treated as any other corporation. ${ }^{39}$ The law additionally allows for simultaneous prosecution under the Health and Safety legislation.

Matters are unclear without court precedent. First, does this law apply to a self-experimenting scientist, or does existing health and safety law take precedence? If this law applies, what is the duty of care to self-experimenting scientists in their employ? Is gross negligence the standard or do universities owe activist paternal duty of care? Since scientists fairly define the proverbial "herd of cats," this could prove vexing to university and hospital managements.

Per a United Kingdom lawyer, in event of a death, “...the University will have to explain to the court ... what steps they took to satisfy themselves that it was safe." The law is extremely vague on what evidence constitutes such proof.

Deaths and harm occur during clinical trials and regulatory permission protects those conducting them from liability unless the trial protocol has been seriously violated. Since ethics review approval is protective, United Kingdom institutions may demand it. United Kingdom institutions may be understandably concerned that an employee's activities could open them to prosecution, regardless of the actual risk.

The United Kingdom is unique at present in the scope of its law. Closest is a Canadian corporate manslaughter law of 2004 requiring employers to take reasonable steps to prevent bodily harm arising from work tasks, with liability for serious negligence. ${ }^{40}$ Ireland introduced a corporate manslaughter bill in 2016 containing a gross negligence standard, which failed to pass. ${ }^{41}$ New Zealand introduced a similar law in 2015, which also failed to pass. ${ }^{42}$ In the United States of America, personal injury law imposes some duty of care on employers, however, there is no evidence this would be used against an institution should a self-experimenting scientist die. Legal precedent sets a fairly high standard for negligence. 
Open questions in ethics review-how useful and costly is ethics review?

The questions on ethical review efficacy raised by Coleman and Bouësseau remain unanswered. ${ }^{43}$ To what degree does ethics review improve: understanding of risks and benefits; decisions to participate; experiences in studies; risk reduction; responsiveness to the community's needs; and how well researchers follow documentation? While all we have is anecdotes and institutional lore, history suggests that ethics review prevents the most egregious abuses of subjects.

We also do not have information on the cost of ethics review to investigators, only anecdotes that for self-experimenting investigators costs can be prohibitive.

\section{Ethics Committee Responses Regarding Investigators as Self-Subjects}

We decided that we needed to know how ethics committees actually think. To probe this, we surveyed ethics offices and committees on their position on self-experimentation. This survey provides a framework for ethics committees to express a view on self-experimentation, including whether selfexperimentation fell within their purview.

\section{Survey method}

Ethics offices at 203 universities or national health services in North America, Central and South America, and Europe, were queried by email whether they had a policy on investigators as self-subjects, and if they required ethics committee approval for self-experimenters. Emails were addressed to the party publicly designated as responsible for answering questions on ethical policy in the institution.

\section{Results}

Twenty-five of the 37 responsive ethics committees had no policy on self-experimenters and 12 did have a policy, giving a 2:1 ratio. Twenty-five responders would require an ethics review, and 12 said they would not require it, which was an identical ratio. However, there was no correlation between having a self-experimenter policy and requiring ethics review. Of the total 48 responses, 11 did not answer the questions. We present a more detailed breakdown in Table 2. Given the usual rates for email responses are in the single digits or below, we consider this to be a good response rate. This response rate is probably because each email was addressed individually by name where possible, some were translated to the language of the nation, and it is the job of ethics committee staff to answer questions such as we asked.
A small number of responses gave substantive reasons for their position. Two ethics committees said it was the ethics committee's job to protect overenthusiastic investigators from harming themselves. One of those would designate a surrogate investigator to obtain informed consent from the self-experimenter, if the protocol was risky enough. One research office considered single-subject experiments to be not meaningful due to an $n$-of- 1 .

The most common position of the one-third of research offices that did not require ethics committee approval was that when the subject and investigator are the same person, there is no justification for intervening. Even when ethics committee approval was not required, however, some encouraged investigators to notify the ethics committee. Four responders said there was no regulation and no guidance on self-experimentation.

Two responders indicated familiarity with self-experimenters at significant numbers, both of them top universities. One did not require an ethics review and said their primary concern is whether or not it would be a solitary selfexperiment, and not a small group experiment as in Huber et al. ${ }^{10}$ This committee informally educates experimenters regarding possible violations of the law in their jurisdiction, and regarding gray areas of what ethics committees think a self-experiment is. The other university familiar with selfexperimenters was the one mentioned above that might assign a surrogate to obtain informed consent if the procedure was deemed risky enough.

\section{Self-Experimenter Views and Motives}

We turn now to why self-experiments are conducted. As ethical concerns center around investigator motives-is the experiment done for the benefit of the patient, the investigator or the wider community-identifying why selfexperimentation is done is significant to establishing its ethical standing. Based on discussions we identified five classes of reasons for self-experimentation:

1. Learning what subjects to a protocol would experience, and noticing effects that might be missed when operating through the relative distance of others. Taking on the role of the first subject in a study can allow the scientist more flexibility in the early stage of an investigation because once approved protocols can be a cumbersome straitjacket.

2. Providing an initial test to confirm that research performed in animals can be translated to humans.

3. Avoidance of the considerable amount of time, expense, and red tape of conducting experiments on others by conducting a self-experiment. ${ }^{14}$

Table 2. Ethics Committee Responses to Self-Experimentation Survey

\begin{tabular}{|c|c|c|c|c|c|c|c|}
\hline Regions & Total & Nonanswers & Net total & No policy & Policy & $\begin{array}{l}\text { Ethics review } \\
\text { required }\end{array}$ & $\begin{array}{l}\text { Ethics review } \\
\text { not required }\end{array}$ \\
\hline United States of America & 25 & 2 & 23 & 17 & 6 & 15 & 8 \\
\hline Europe, Cen. and S. America & 7 & 1 & 6 & 3 & 3 & 4 & 1 \\
\hline United Kingdom and Canada & 16 & 8 & 8 & 5 & 3 & 6 & 3 \\
\hline All regions & 48 & 11 & 37 & 25 & 12 & 25 & 12 \\
\hline
\end{tabular}

The questions were: Is there a policy on self-experimentation? And would they require an ethics review for self-experiments? 
4. To pilot on one person an experimental procedure that would be impractically resource intensive or expensive if performed on many people. 9,44

5. Proving that something is safe/true when no one else will believe you. ${ }^{2}$

\section{Risks of Self-Experimentation}

A concern in the survey of ethics committees was that a self-experimenter might be exposing themselves to undue risk. "Undue" is of course a judgement, but is the balance between the risk and the benefit. In this section we address the issue of risk, in the next section we address the issue of benefit. As noted above, one survey respondent explicitly stated that an $n$-of- 1 self-experiment could not be meaningful, reflecting concern about this side of the equation. We address this specifically below.

The ethical right of scientists to expose themselves to risks appears clear as long as they are competent, as indicated in Nuremburg principle 5. But what are the actual risks?

\section{Risk of death in self-experiments}

Risk of death from self-experiments does not appear likely in the present era. Weisse recorded $8(1.72 \%)$ deaths out of his 465 identified self-experiments in 203 years. This historic mortality rate may be comparable to the approximate $1 \%$ acute mortality rate in orthopedic surgery. ${ }^{45}$ However, all but one death was from self-inoculation with an infectious disease, and five of them occurred in the 19th century when the germ theory of disease was being investigated. The last self-experiment death was Alexander Bogdanov in 1928, from transfusion with an incompatible blood type. Since that time, there have been at least 190 selfexperiments documented in literature, without a single death. $^{3,4}$

\section{Risk of nonfatal self-harm}

We could not find sufficient data on rates of significant nonfatal harm from self-experiments, just cautionary cases. John Stapp, a United States Air Force officer, physician, and pioneer in studying the effects of acceleration and deceleration forces on humans, acquired permanent vision problems in 1954 after sustaining his last deceleration of 46.2 G. ${ }^{46} \mathrm{He}$ did not do any more deceleration experiments on himself after this. Before ending his acceleration selfexperiments, Stapp suffered broken bones and concussion. Philip Kennedy's 2014 operation to implant electrodes into his speech center caused him temporary loss of the ability to speak. ${ }^{12}$ Nikola Tesla experienced burns to his eyes and skin from X-ray exposure. ${ }^{47}$

These incidents indicate there is a case to be made for urging scientists planning self-experiments to be careful and submit their experimental plans for external review. However, data are sparse, and unrecognized risk of self-harm does not appear to be a serious problem.

\section{Risk discussion}

Self-harm (as well as death) could come from risks taken for one of three reasons.
1. The risk could be known, acknowledged, and accepted. As noted above, a scientist may understand the risk, but consider it unethical to expose someone else to risks they are not willing to take themselves. John Stapp and Philip Kennedy were well aware of their risk and accepted it.

2. The risk could be known by those knowledgeable in the field, but not by the experimenter. We have no examples of this among scientists. Self-experimenters appear to be motivated to find out everything they can about an experiment before trying it.

3. The risk could be unknown to anyone at the time. Nikola Tesla did not know the dangers of high doses of X-rays, nor did Marie Curie understand the dangers of radiation. With others in the early days of radiation science, they paid for their curiosity with injury or death. $^{48}$

Risk of death or harm boils down to two issues. First, has the self-experimenter evaluated and understood the risks? This is possible in the first and second case, obviously it is not possible in the third case. Second, do they accept the risks?

The former is a reasonable cause to suggest oversight and review. The second is a fundamental ethical choice on par with whether people should be allowed to base-jump, or free-climb El Capitan. Wrapped in with this second ethical question is how much benefit there may be to the experimenter and others from the experiment.

\section{Benefits and Meaningfulness of Self-Experimentation}

Case reports can have the following functions: (I) descriptions of new diseases; (II) study of mechanisms; (III) discovery of new therapies; (IV) recognition of side effects; and (V) education.

—Yì-Xiáng J. Wáng (2014)

\section{n-of-1 and self-experiments}

The question of self-experimentation benefits is inextricable from whether such a "low statistical power" $n$-of- 1 experiment has meaning. Two of us have been told vehemently that $n$-of- 1 self-experimentation is worse than useless. Below we argue that this is not true, and that $n$-of- 1 experiments can be highly informative.

We start by noting that case reports have been a foundation of medicine from the time of the Ancient Egyptians, Hippocrates, and Galen. ${ }^{49,50}$ The clinical case report remains a major part of modern medical science. ${ }^{51,52}$ In the current century two notable single case reports are a recovery from rabies ${ }^{53}$ and the Berlin patient HIV cure. ${ }^{54}$ The only difference between a case report and a self-experiment is that a case report is an uncontrolled, random $n$-of- 1 observation, whereas a self-experiment can be done under planned, controlled conditions.

There is considerable work by physicians on $n$-of- 1 clinical trial methodology as discussed by Lillie et al., using timeseries and monitoring devices or tests to track endpoints. ${ }^{55} n$ of 1 trialing stems from physician's routine use of trial and error to find treatments that work. Lillie's $n$-of- 1 trial considerations apply equally to self-experimenters, including the benefit of making results available to combine later. 
We are also finding out more about how individual humans differ, and $n$-of- 1 or self-experiments can shed light on differences large trials tend to smooth out. An $n$-of- 1 trial removes that source of variation. Michael Snyder's massively parallel self-analysis experiment, the Snyderome, is an example of this. ${ }^{9} \mathrm{He}$ detected changes in his state that were within the "normal" range as defined by population distributions, but were nevertheless meaningful. Thus, $n$-of- 1 experiments can also give a different type of information.

Further, given the reproducibility crisis in biomedical science, $n$-of- 1 validation of animal observations in a human should aid transition to full-scale clinical or field trial.

\section{Self-experiment results are usually confirmed}

As Altman and Roberts discuss, self-experiments, even in the soft and complex fields of behavior and psychology, have usually been confirmed. ${ }^{3,56}$ Altman concluded that scientists have little incentive to falsify results of selfexperiments. Such motives tend to appear farther down the line after commitment of resources.

We only found one unconfirmed example, Max von Pettenkover's failure to become seriously ill with cholera after drinking a culture of Vibrio cholerae, however, we believe there are other self-experiments that would not stand. One possible reason why such examples could be missing is that self-experimenting scientists did further work to verify their result, and if it did not hold up, would be unlikely to publish. This bias is recognized in case report literature. However, we do not think it is a serious problem.

\section{Experimental design in self-experiments}

A common theme in all the self-experimental literature cited above is that the experiment is designed to provide appropriate controls, a suitable quality of analysis, and as independent a process as is practical. Experiments can be designed so that third parties make measurements or perform assays to eliminate bench error, bias, or self-assessment error. By having third parties take samples, perform tests, make assessments, and confirm identity, self-experimenters can avoid questions of credibility and veracity as well. We rec- ommend that self-experimenting researchers do this when it is practical.

An optimum self-experiment can be designed as a doubleblind, placebo controlled, randomized controlled trial in many cases. Depending on the experiment, blinding, and using crossover in contralateral limbs, skin, or organs could be appropriate. In most cases, time series will be appropriate and washout and normalization periods are needed in addition to blinding. Double-blind design is not common in self-experiments, but there are examples. ${ }^{10,11,57}$

\section{Self-experiment value}

Weisse and others express the view that moving research ahead is most important, and also that the value to the many outweighs discomfort or risk for one. ${ }^{3,4}$ Dresser and Sacks advocated the value of self-testing to further their own knowledge.$^{58,59}$ It may be impossible to know the value of a piece of research until sometimes decades later. Thus, we conclude from the discussion above, and the support of highly respected scientists and clinicians, that single-subject experimental results can be valuable and important.

\section{Survey of Prominent Scientists Views Regarding Self-Experiments}

The review of risks and benefits of self-experimentation above is an academic analysis. So is this how practicing scientists see self-experimentation? Again, we turned to a survey to find out. In the process, we realized that nobody had ever attempted to classify kinds of self-experiments, and several of them are quite trivial. These classifications are visible in Figures 3 and 4.

\section{Survey method}

A total of 1072 members of the National Academy of Sciences, the Royal Society, and the European Academy of Sciences were sent an online survey link by email consisting of questions directly addressing the questions presented in Figures 3 and 4 . These scientists were chosen because they are the most recognized, and in secure positions, many retired. Over 3 months, 52 responders answered the question

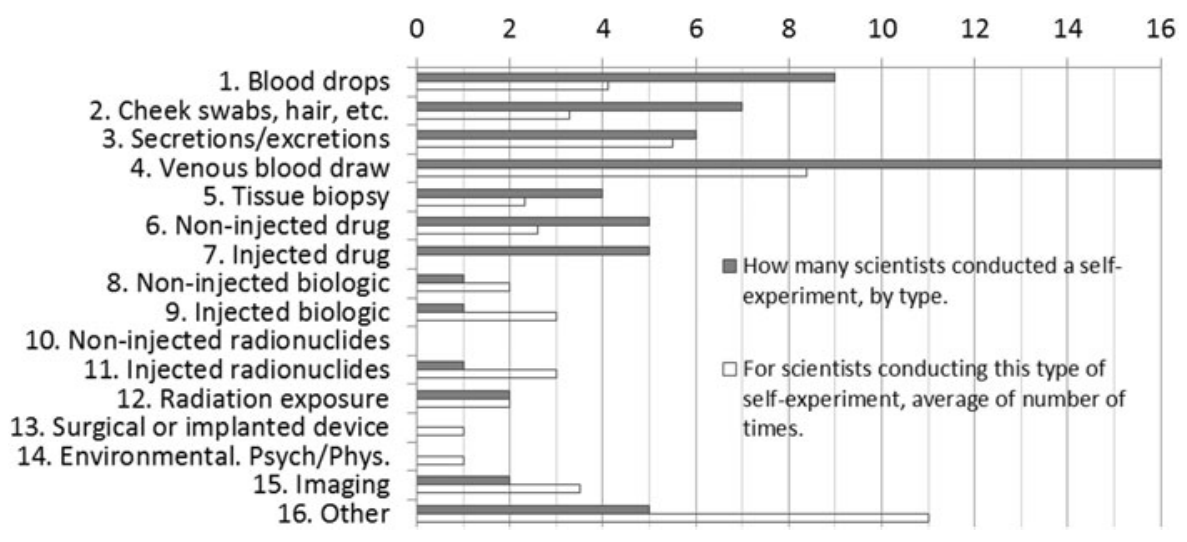

FIG. 3. The number of respondents who performed various types of self experiments—versus—average (mean) number of times that scientists who experimented on themselves reported conducting each type of experiment. Multiple types of self experiments could be performed by one scientist, and 26 of our sample of 52 responders are represented here. 26 did not conduct self-experiments. 


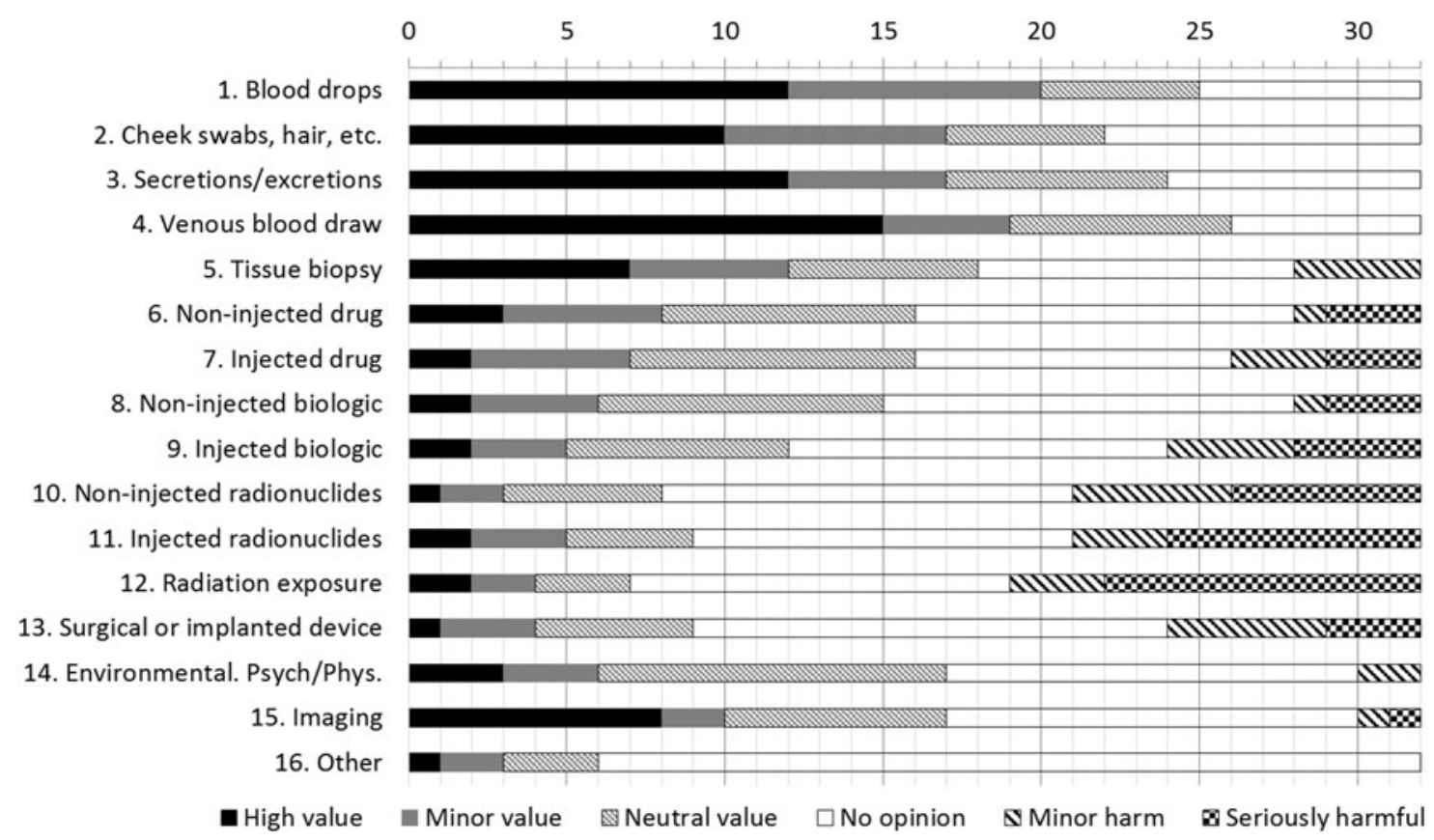

FIG. 4. Perceived value to science of each type of self-experiment. We considered that selecting no opinion is equivalent to expressing a neutral opinion on the value of self-experiments.

on types of self-experiments they had done, but only 32 answered about the value of these experiments. This $4.8 \%$ response rate is fair for general bulk email, and the sample sizes (52 and 32) did rise to minimal $t$ test significance. This survey was too large to administer with individually written emails, so it required a click-through to activate. With phishing concerns, click-through may have suppressed many responses. The impersonal look may have caused some to treat the survey as junk email without fully reading. The presence of links and format may have activated automatic spam filters as well.

\section{Results}

Out of the 52 respondents, 26 did not conduct selfexperiments and 26 did. All 26 self-experimenters filled out the question on the number of times they had selfexperimented, and, 6 got ethics committee approval. Of these 26 self-experimenters, 10 of them performed serious self-experiments of types 5-16 as shown in Figures 3 and 4.

The low response rate means that we cannot claim these results are typical. However, they do reflect the overall risk:benefit balance discussed above, in that the most widely practiced procedures, and those with the most perceived benefit, are ones that are least risk. The split between those who sought ethics review and those that did not is consistent with the fraction of institutions having ethics committees with policies that cover self-experimentation.

\section{Investigator Self-Experimenter Scenarios-Practice in Academia, Industry, and the Public}

We wanted to bring our ethics and efficacy discussion down to earth by presenting scenarios drawn from real world cases of self-experimentation. To this end, we have five examples.

\section{Independent single-subject investigator}

While an independent investigator experimenting on themselves has no legal or ethical obligation to consult an ethics committee, we think it should be easily available on a voluntary basis both for review and to ease publication. There may be merit to codifying this as a streamlined, flexible review bounded by clarifying risk.

\section{Investigator participating in an ethics committee approved study at a small or startup company}

Similar to an independent investigator, a startup founder self-experimenter has no requirement to consult an ethics committee. If founder investigators in small companies get ethics committee approval and make themselves a subject of an ethics committee approved protocol, there is neither regulation nor ethics imperative that obligates them to tell the ethics committee that they will be a subject unless that ethics committee chooses to ask. Whether an ethics committee cares to know is a matter of the ethics committee's choice.

\section{Investigator working at a large pharmaceutical firm}

Whether a scientist at a large pharmaceutical company makes themselves a subject on an ethics committee approved protocol may be a matter of company policy. There are multiple possible scenarios in this case.

First, an investigator on a project may try an experiment in the lab without approval or consulting anyone, often, based on an accident. Historically, this is fairly common. Searle discovered Aspartame by accidentally tasting a drug synthesis intermediate. ${ }^{60}$ Hoffman famously discovered LSD by accidentally ingesting it, and then deliberately dosing himself. ${ }^{61}$ Hoffman also self-tested Hydergine, which became a major drug for Sandoz. It would seem then that companies with overly 
restrictive policies may hurt their profitability by preventing potential discoveries. However, as we discussed, modern health and work safety legislation in the United Kingdom puts obligations on employers to provide a "safe work environment," meaning an environment where no harm can come to an employee. As a self-experiment could be harmful, this legal/ regulatory structure strongly discourages companies from allowing self-experimentation in the Searle/Hoffman model.

Second, an investigator may decide submit to their own protocol. There is a reasonable argument that investigators could feel under pressure to do so from superiors or peers. We have anecdotally heard this was the case in one major pharmaceutical company in the past. We think companies should strive to strike a balance between preventing coercion, and allowing qualified scientists to be subjects in their experiments should they wish to be, and that an external review would be best.

\section{Investigator/employee of a pharmaceutical firm uses a drug to treat their own disease}

Before approval, a scientist could ask the company for permission to use a treatment, which would put the scientist in the position of a phase 2 or 3 clinical trial subject. If the company is still in phase 1 or 2 it can present issues for data analysis. If his disease is serious enough, the investigator may not be willing to wait. Similarly, if the scientist treats himself for condition B and the clinical trial is for condition A, this could also present problems for data analysis.

Use of the drug by the employee would be a matter of compassionate provision of the materials on the part of the company. With "right to try" laws in a majority of states, and because people can administer what they want to themselves, this should be acceptable, ${ }^{62}$ although there are certainly concerns for those running a trial. ${ }^{63}$ As above, the most fundamental issue for the company is that problematic data at the wrong stage can potentially destroy a potential new product, by requiring expansion of the study to numbers that are beyond the budget.

If the company denies permission, which is quite understandable to protect their nascent product, then we get into another area of law. The World Intellectual Property Organization finds that experimental and research use of an invention is legal in most countries. ${ }^{64}$ In the United States, there is a common-law exception allowing de minimis experimental use that is strictly limited to an individual's personal interest without any intention to profit. This was enlarged by the Hatch-Waxman Act with amendment $\S 271(\mathrm{e})(1)$ the "Safe Harbor Provision.",65 This allows "uses reasonably related" to pursuing FDA approval, although it does not necessarily require that an FDA application be filed. ${ }^{66}$

If the company denies permission, the simplest solution for the interested investigator-user of the drug is to synthesize it themselves. Often, this should be within their abilities. If not, then a contract chemistry company could make it. Or, the scientist could simply take it from the employer. This latter could be considered a kind of theft from the company, but might be overlooked for public relations reasons.

Considering this case of an individual with a disease in light of these elements of law, the person would pass the narrow de minimis experimental use common-law exception as it would be personal interest and not for profit. It would also fall under the Safe Harbor Provision of $\S 271(\mathrm{e})(1)$, as long as the use was recorded, with sufficient follow-up data collected that could be made available to regulators at some future date to fulfill the "reasonably related" clause.

\section{Nonscientist self-experimenters brought into a later study-experiments and biohacking}

Nonscientists conduct experimental procedures on themselves, and some are quite knowledgeable and keep very good records of what they do. For instance, Bill Haast, Tim Friede, and others pioneered immunization to venomous animals. ${ }^{67}$ Biohacking is bringing sizeable numbers of amateurs to experiment on themselves. Many, if not most, biohacking experiments today are misguided or fail. ${ }^{68}$ However, some achieve significant results. 69

Bringing nonscientist self-experimenters into a study presents issues for an ethics committee in the context of Helsinki.

First, it is self-experimenter protocols rather than the investigator's, and there may be variation over time and between individuals. Second, whether the experiments occur is not directed by the investigator. This has similarity to studies of recreational drug users and addicts, however, selfexperimenters may understandably take umbrage at such a comparison. Third, because the investigator does not have control, it will be impossible for the investigator to provide safety assurances. Fourth, the investigator may be limited to making suggestions to people who may be ahead of the investigator in practical ways. This requires that the investigator have quite a bit of flexibility, in ways that do not fit the Helsinki framework. Last, participants may have opinions of their own on how things should go, and expect benefits from participation. This latter is part of Helsinki.

This kind of study requires a collaborative approach rather than the Helsinki model. Studies of Native American communities created principles of community-based participatory research. ${ }^{70}$ However, self-experimenter studies are really a form of collaboration, not the top-down model of the investigator in charge.

Our conclusion is that passive collection of self-experiment data from nonscientists does not require an ethics committee. Some petition strenuously to be studied and taken seriously by scientists, and this leans strongly in the direction of justifying nonrequirement of an ethics committee. We think that an ethics committee should accept such study applications, and make allowances for flexibility as we have discussed. However, such studies technically fall outside the Helsinki framework and this needs recognition.

\section{Conclusions on Ethics and Value of Self-Experiments}

The history of ethics founded in Nuremberg article 5 explicitly approves of self-experiments when an experiment could do harm, which implicitly includes experiments not expected to do harm. No contravention to this appears in later documents built upon the Nuremberg foundation. Morally, self-experimentation signals confidence and dedication. Thus, formal and moral authority of ethics allows investigators to use themselves as experimental subjects. The history of science shows that self-subject experiments are significant and sometimes have great value to society.

In addition, within the legalistic framework of modern day ethics bureaucracy, scientists running studies represent 
the definition of informed consent. ${ }^{71}$ Qualified scientists who run experiments on themselves are also distinct from family members, graduate students, staff, and others who may be subject to any significant level of coercion. There are instances when a graduate student or staff member might undertake a self-experiment without coercion. However, we are unclear how a bureaucratic institution can tell the difference, except for the occasional fait accompli. Further consideration of this could be helpful.

Ethics committee review is not required for selfexperimenters under Helsinki, and we should remember that history shows that scientists (and nonscientists) will perform self-experiments despite knowing that such an experiment would be disapproved of and suffering serious social or employment repercussions for doing so. ${ }^{72}$ Our conversations with colleagues indicate that self-experimentation is usually conducted secretly today and that self-experiments are quite common. Thus, attempting to ban self-experiments would be a self-defeating exercise that probably does more harm than good.

We suggest a compromise between institutional hostility on one hand and individual overenthusiasm on the other. The practical authority of an ethics committee over selfexperiments, should an institution choose to intervene, is persuasion, regardless of formal authority, because history shows that self-experimenters ignore the rules and superiors may intentionally turn a blind eye. However, obtaining ethics committee approval, allows the experimenter to have their work peer reviewed before undergoing their experiment. Taking this step also prevents publication problems with journals that require ethics committee review, even though the journals should make an exception for such studies. We think ethics committee review should be available for self-experimenters, but voluntary. Ethics committee review for self-experimenters should also be much simplified and inexpensive.

If self-experimentation is formally recognized and review is streamlined, it may be more frequent that self-experimenting scientists seek such review. Self-experimenters should not have attempts made to terminate their employment bar them from use of facilities, nor be barred from using their own tissues in most circumstances. Similarly, if these consequences stop, then scientists may come out of the closet about their selfexperiments, and this, in turn, should result in improving experimental methodologies, and hence, results.

By extension, it could make sense that a self-experimenter with or without ethics committee approval should have a simplified procedure to notify clinical trial regulatory agencies such as the FDA and the European Commission of their intent, and have a venue for reporting data.

\section{Authors Contributions}

G.C. provided guidance and several subsections. W.B. provided several subsections and use of his web site to ensure email responses could not be requested by FOIA. All three authors collaborated on the surveys design. B.H. was primary author.

\section{Author Disclosure Statement}

The authors have conducted self-experiments in their careers. The lead author conducted a self-experiment with the intent of submitting data to the FDA. This project received no direct grant funding, only shared resources.

\section{References}

1. Azad M. Q \& A: Barry Marshall. Nature 2014;514:S6.

2. Hollmann W. Werner Forssmann, Eberswalde, the 1956 nobel prize for medicine. Eur J Med Res 2006;11:409-412.

3. Altman LK. Who Goes First? The Story of SelfExperimentation in Medicine. Berkeley, CA: University of California Press, 1998.

4. Weisse AB. Self-experimentation and its role in medical research. Tex Heart Inst J 2012;39:51-54.

5. Marshall BJ, Armstrong JA, McGechie DB, Glancy RJ. Attempt to fulfil Koch's postulates for pyloric Campylobacter. Med J Aust 1985;142:436-439.

6. Prescott J. Deadly allies. Canada's secret war 1937-1947. Can Vet J 1991;32:366.

7. Fiks AP, Buelow PA. Self-experimenters: Sources for Study. Westport, CT: Greenwood Publishing Group, 2003, pp. 292.

8. Landhuis E. Do it yourself? When the researcher becomes the subject. Science 2016; [Epub ahead of print]; DOI: 10.1126/science.caredit.a1600160.

9. Snyder M. Q \& A: The snyderome. Genome Biol 2012;13: 147.

10. Huber R, Bross F, Schempp C, Gründemann C. Arnica and stinging nettle for treating burns-a self-experiment. Complement Ther Med 2011;19:276-280.

11. Gwern. LSD microdosing RCT, 2017. http://gwern.net/ LSD-microdosing (accessed January 23, 2018).

12. Piore A. To study the brain, a doctor puts himself under the knife- how one of the inventors of brain-computer interfaces ended up getting one himself. MIT Technology Review, 2015. https://technologyreview.com/s/543246/to-study-the-brain-adoctor-puts-himself-under-the-knife/ (accessed June 10, 2017).

13. Poldrack RA, Laumann TO, Koyejo O, Gregory B, Hover A, Chen M-Y, Gorgolewski KJ, Luci J, Joo SJ, Boyd RL, Hunicke-Smith S, Simpson ZB, Caven T, Sochat V, Shine JM, Gordon E, Snyder AZ, Adeyemo B, Petersen SE, Glahn DC, Reese Mckay D, Curran JE, Göring HHH, Carless MA, Blangero J, Dougherty R, Leemans A, Handwerker DA, Frick L, Marcotte EM, Mumford JA. Long-term neural and physiological phenotyping of a single human. Nat Commun 2015;6:8885.

14. Preston E. Biotech execs in search of human guinea pigs find eager subjects: Themselves. Stat News- In the Lab, 2017, 2016. https://statnews.com/2016/07/07/guinea-pigbiotech-ceo/ (accessed May 9, 2017).

15. Carrick P. Medical Ethics in the Ancient World. Washington, DC: Georgetown University Press, 2001.

16. Antoniou SA, Antoniou GA, Granderath FA, Mavroforou A, Giannoukas AD, Antoniou AI. Reflections of the hippocratic oath in modern medicine. World J Surg 2010;34:3075-3079.

17. Percival T. Medical ethics; or, a code of institutes and precepts, adapted to the professional conduct of physicians and surgeons. To which is added an appendix; containing a discourse on hospital duties. Manchester, England: S. Russell, for J. Johnson and R. Bickerstaff, 1803. https://archive.org/ details/b21935014 (accessed May 9, 2017).

18. Riddick FA. The code of medical ethics of the American Medical Association. Ochsner J 2003;5:6-10.

19. Kubar O. Research involving human subjects: Ethics and law in early 20th century Russia. Bull Medical Ethics 2001;13-17.

20. Encyclopedia Judaica, Gale Group. Nazi medical experiments, 2008. http://jewishvirtuallibrary.org/background-andoverview-of-nazi-medical-experiments (accessed December $15,2017)$. 
21. Harris S. Japanese biological warfare research on humans: A case study of microbiology and ethics. Ann N Y Acad Sci 1992;666:21-52.

22. Arnold L, Smith M. Chapter 8: Buffalo-1956. In: Britain, Australia and the Bomb. London, United Kingdom: Palgrave Macmillan, 2006, pp. 138-171.

23. Rosenberg H. Atomic Soldiers. Boston, MA: Beacon Press, 1980.

24. Reverby SM. "Normal Exposure" and inoculation syphilis: A PHS "Tuskegee" doctor in Guatemala, 1946-1948. J Policy History 2011, pp. 6-28.

25. World Medical Association. Declaration of Helsinki: Ethical Principles for Medical Research Involving Human Subjects. Helsinki, Finland: World Medical Association (WMA), 2008.

26. World Medical Association. World Medical Association declaration of Helsinki: Ethical principles for medical research involving human subjects. JAMA 2013;310:2191-2194.

27. Ryan KJ, Brady JV, Cooke RE, Height DI, Jonsen AR, King P, Lebacqz K, Louisell DW, Seldin DW, Stellar E, Turtle RH. The Belmont report-ethical principles and guidelines for the protection of human subjects of research, 1979. https://hhs.gov/ohrp/regulations-and-policy/belmontreport/ (accessed May 9, 2017).

28. Heller J. Syphilis victims in U.S. study went untreated for 40 years. New York Times, 1972. http://nytimes.com/1972/ 07/26/archives/syphilis-victims-in-us-study-went-untreated-for40-years-syphilis.html (accessed May 9, 2017).

29. $93^{\text {rd }}$ Congress. National Research Act. Washington, DC: GPO, 1974. https://gpo.gov/fdsys/pkg/STATUTE-88/pdf/ STATUTE-88-Pg342.pdf (accessed June 10, 2017).

30. Graf HP, Cole D. Ethics-committee authorization in Germany. J Med Ethics 1995;21:229-233.

31. Yanagawa H, Katashima R, Takeda N. Research ethics committees in Japan: A perspective from thirty years of experience at Tokushima University. J Med Invest 2015;62:114-118.

32. DHHS. Human subject protection: Foreign clinical studies not conducted under an investigational new drug application. Final Rule April 28 2008, effective October 27 2008, 2008. https://www.fda.gov/downloads/regulatoryinformation/ guidances/ucm294729.pdf (accessed March 9, 2017).

33. Strosberg MA, Gefenas E, Loue S, Philpott S. Building research ethics capacity in post-communist countries: Experience of two fogarty training programs. J Empir Res Hum Res Ethics 2013;8:28-39.

34. Zeng L, Liang W, Pan J, Cao Y, Liu J, Wang Q, Wang L, Zou Y, Wang K, Kong L, Xie H, Xu W, Li W, Zhao W, Mi S, Chen Y, Cheng S, Li X, Cao Q, Zeng X, Wang N. Do chinese researchers conduct ethical research and use ethics committee review in clinical trials of anti-dementia drugs? An analysis of biomedical publications originating from China. J Alzheimers Dis 2016;52:813-823.

35. Thatte UM, Marathe PA. Ethics committees in India: Past, present and future. Perspect Clin Res 2017;8:22-30.

36. ICH. E6(R2) Good Clinical Practice - Step 2 Draft. Rockville. MD: FDA.[FDA (Series Editor), 2015. https://www .fda.gov/downloads/Drugs/Guidances/UCM464506.pdf (accessed June 10, 2017).

37. ICH. Guidance for Industry E6 Good Clinical Practice: Consolidated Guidance. Rockville. MD: FDA, 1996. https:// www.fda.gov/downloads/Drugs/Guidances/UCM464506.pdf (accessed June 10, 2017).

38. Food and Drug Administration. Federal Policy for the Protection of Human Subjects-Final rule. Washington,
DC: GPO, 2017. https://www.gpo.gov/fdsys/pkg/FR-201701-19/pdf/2017-01058.pdf (accessed June 10, 2017).

39. Parliament. Corporate Manslaughter and Corporate Homicide Act 2007. London, United Kingdom: The National Archives, 2007. https://legislation.gov.uk/ukpga/2007/19/contents (accessed June 10, 2017).

40. Parliament. Westray Bill (Bill C-45), 2004. http://ccohs.ca/ oshanswers/legisl/billc45.html (accessed December 19, 2017).

41. McGrath J. Successive governments fail to act on glaring absence of Irish corporate manslaughter law. Independent, 2017. https://independent.ie/business/irish/successive-governmentsfail-to-act-on-glaring-absence-of-irish-corporate-manslaughterlaw-35980658.html (accessed Nov 22, 2017).

42. Nicholson G, Welsh O. New Zealand rejects an offence of corporate manslaughter for workplace deaths, 2015. https:// kensingtonswan.com/news-updates-and-events/new-zealandrejects-an-offence-of-corporate-manslaughter-for-workplacedeaths/ (accessed December 19, 2017).

43. Coleman $\mathrm{CH}$, Bouësseau M-C. How do we know that research ethics committees are really working? The neglected role of outcomes assessment in research ethics review. BMC Med Ethics 2008;9:6.

44. Chen R, Mias GI, Li-Pook-Than J, Jiang L, Lam HY, Chen R, Miriami E, Karczewski KJ, Hariharan M, Dewey FE, Cheng Y, Clark MJ, Im H, Habegger L, Balasubramanian S, O'Huallachain M, Dudley JT, Hillenmeyer S, Haraksingh R, Sharon D, Euskirchen G, Lacroute P, Bettinger K, Boyle AP, Kasowski M, Grubert F, Seki S, Garcia M, Whirl-Carrillo M, Gallardo M, Blasco MA, Greenberg PL, Snyder P, Klein TE, Altman RB, Butte AJ, Ashley EA, Gerstein M, Nadeau KC, Tang H, Snyder M. Personal omics profiling reveals dynamic molecular and medical phenotypes. Cell 2012;148:1293-1307.

45. Bhattacharyya T, Iorio R, Healy WL. Rate of and risk factors for acute inpatient mortality after orthopaedic surgery. J Bone Joint Surg Am 2002;84-a:562-572.

46. Giappettino J. His swift rides saved thousands of lives. The Day, 1984. https://news.google.com/newspapers?id=uTdSAAAAI BAJ\&sjid=XjYNAAAAIBAJ\&pg=1260\%2C1777082 (accessed Nov 22, 2017).

47. Hrabak M, Padovan RS, Kralik M, Ozretic D, Potocki K. Scenes from the past: Nikola Tesla and the discovery of Xrays. Radiographics 2008;28:1189-1192.

48. Inkret WC, Meinhold CB, Taschne JC. Radiation and risk: A hard look at the data - protection standards. Los Alamos Sci 1995;23:117-123.

49. Vargas A, Lopez M, Lillo C, Vargas MJ. [The Edwin Smith papyrus in the history of medicine]. Rev Med Chile 2012; 140:1357-1362 (Article in Spanish).

50. Serageldin I. Ancient Alexandria and the dawn of medical science. Glob Cardiol Sci Pract 2013;2013:395-404.

51. Nissen T, Wynn R. The clinical case report: A review of its merits and limitations. BMC Res Notes 2014;7:264.

52. Wáng Y-XJ. Advance modern medicine with clinical case reports. Quant Imaging Med Surg 2014;4:439-443.

53. Willoughby RE, Jr., Tieves KS, Hoffman GM, Ghanayem NS, Amlie-Lefond CM, Schwabe MJ, Chusid MJ, Rupprecht CE. Survival after treatment of rabies with induction of coma. N Engl J Med 2005;352:2508-2514.

54. Hutter G, Nowak D, Mossner M, Ganepola S, Mussig A, Allers K, Schneider T, Hofmann J, Kucherer C, Blau O, Blau IW, Hofmann WK, Thiel E. Long-term control of HIV by CCR5 Delta32/Delta32 stem-cell transplantation. $\mathrm{N}$ Engl J Med 2009;360:692-698. 
55. Lillie EO, Patay B, Diamant J, Issell B, Topol EJ, Schork NJ. The n-of-1 clinical trial: The ultimate strategy for individualizing medicine? Per Med 2011;8:161-173.

56. Roberts S. Self experimentation. In: Lattal KA, Perone M. (eds): Handbook of Research Methods in Human Operant Behavior. New York: Plenum Publishing Co., 1998, pp. 619655 (Nato Science Series B).

57. Dittrich A. Alteration of behavioural changes induced by 3,4,5-trimethoxyphenylethylamine (mescaline) by pretreatment with 2,4,5-trimethoxyphenylethylamine. Psychopharmacologia 1971;21:229-237.

58. Dresser R. Personal knowledge and study participation. J Med Ethics 2014;40:471-474.

59. Sacks O. Altered states: Self-experiments in chemistry, 2012. https://newyorker.com/magazine/2012/08/27/alteredstates-3 (accessed December 20, 2017).

60. Whitehouse CR, Boullata J, McCauley LA. The potential toxicity of artificial sweeteners. AAOHN J 2008;56:251-259.

61. Hoffmann A. LSD, My Problem Child. New York: McGrawHill, 1980. https://archive.org/details/LSDMyProblemChildBy Dr.AlbertHoffman (accessed June 10, 2017).

62. Thierer A. The Right to Try and the Future of the FDA in the Age of Personalized Medicine. Fairfax, VA: George Mason University: Mercatus Center George Mason University, 2016. https://papers.ssrn.com/sol3/papers.cfm?abstract_id= 2807973 (accessed July 4, 2017).

63. Jacob JA. Questions of safety and fairness raised as rightto-try movement gains steam. JAMA 2015;314:758-760.

64. Secretariat-WIPO. Exceptions and Limitations to Patent Rights: Experimental Use and/or Scientific Research. Geneva, Switzerland: World Intellectual Property Organization, 2013. [WIPO (Series Editor). http://wipo.int/meetings/en/doc details.jsp?doc_id=256318 (accessed May 9, 2017).

65. $98^{\text {th }}$ Congress. Public Law 98-417 Drug Price Competition and Patent Term Restoration Act of 1984. Washington, DC: GPO, 1984. https://gpo.gov/fdsys/pkg/STATUTE-98/pdf/ STATUTE-98-Pg1585.pdf (accessed May 9, 2017).
66. NYS-TLC. Experimental use exception to patent infringement, 2014. http://nysstlc.syr.edu/experimental-use-exceptionto-patent-infringement/. (accessed March 9, 2017).

67. Benoit N. The immunizers, 2010. http://normanbenoit.com/ immunisers.htm (accessed March 9, 2017).

68. Brown KV. This guy just injected himself iwth a DIY HIV treatment on Facebook live, 2017. https:/gizmodo.com/ this-guy-just-injected-himself-with-a-diy-hiv-treatment-1819 659724 (accessed May 30, 2018).

69. Maloney D. Biohacking lactose intolerance, 2018. https:// hackaday.com/2018/02/14/biohacking-lactose-intolerance/ (accessed: May 30, 2018).

70. Santos L. Genetic research in native communities. Prog Community Health Partnersh 2008;2:321-327.

71. Ball MP, Bobe JR, Chou MF, Clegg T, Estep PW, Lunshof JE, Vandewege W, Zaranek AW, Church GM. Harvard Personal Genome Project: Lessons from participatory public research. Genome Med 2014;6:10.

72. Nossaman BD, Scruggs BA, Nossaman VE, Murthy SN, Kadowitz PJ. History of right heart catheterization: 100 years of experimentation and methodology development. Cardiol Rev 2010;18:94-101.

73. Hippocrates (Circa 400 BC, Translation 2002.) Hippocratic oath I $\pi \pi \boldsymbol{o} \kappa \rho \boldsymbol{\alpha} \tau \boldsymbol{\sigma} v \varsigma \boldsymbol{o} \rho \kappa \boldsymbol{o}$. In Greek Medicine; History of Medicine; National Library of Medicine; National Institutes of Health. Bethesda, MD: NIH. https://nlm.nih.gov/ hmd/greek/greek_oath.html (accessed July 4, 2017).

Address correspondence to:

Brian P. Hanley

Butterfly Sciences

P.O. Box 2363

Davis, CA 95616

E-mail: brian.hanley@ieee.org

Received: February 6, 2018

Accepted: June 20, 2018

\section{Appendix}

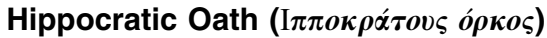

I swear by Apollo the physician, and Asclepius, and Hygieia and Panacea and all the gods and goddesses as my witnesses, that, according to my ability and judgement, I will keep this Oath and this contract:

To hold him who taught me this art equally dear to me as my parents, to be a partner in life with him, and to fulfill his needs when required; to look upon his offspring as equals to my own siblings, and to teach them this art, if they shall wish to learn it, without fee or contract; and that by the set rules, lectures, and every other mode of instruction, I will impart a knowledge of the art to my own sons, and those of my teachers, and to students bound by this contract and having sworn this Oath to the law of medicine, but to no others.

I will use those dietary regimens which will benefit my patients according to my greatest ability and judgement, and I will do no harm or injustice to them.

I will not give a lethal drug to anyone if I am asked, nor will I advise such a plan; and similarly I will not give a woman a pessary to cause an abortion.
In purity and according to divine law will I carry out my life and my art.

I will not use the knife, even upon those suffering from stones, but I will leave this to those who are trained in this craft.

Into whatever homes I go, I will enter them for the benefit of the sick, avoiding any voluntary act of impropriety or corruption, including the seduction of women or men, whether they are free men or slaves.

Whatever I see or hear in the lives of my patients, whether in connection with my professional practice or not, which ought not to be spoken of outside, I will keep secret, as considering all such things to be private.

So long as I maintain this Oath faithfully and without corruption, may it be granted to me to partake of life fully and the practice of my art, gaining the respect of all men for all time. However, should I transgress this Oath and violate it, may the opposite be my fate.National Library of Medicine. Translated by Michael North, 2002. ${ }^{73}$ 